\title{
A sílaba na relação com a escrita: ataques ramificados na escrita de crianças dos segundo e quarto anos - um estudo a partir do EFFE-On
}

\author{
Moisés Pampim, Diana Reis, Cristiana Mendonça \& Iolanda Fernandes \\ Universidade de Lisboa
}

\begin{abstract}
:
The syllable is a unit of the phonological system of human languages that has been the subject of numerous studies in language and language acquisition. Using longitudinal data from the online corpus EFFE-On, this article focuses on the evaluation of children's written performance with respect to the order of acquisition of the syllable structure, in particular the analysis of branching Onsets (obstruent+liquid). The study focuses on the performance of second and fourth graders in the Lisbon area and will allow us to describe the relationship between phonological and orthographic knowledge in children attending the first years of elementary education.
\end{abstract}

Keywords: syllable; acquisition of syllable structure; written performance; branching Onsets; phonological knowledge; orthographic system; European Portuguese

Palavras-chave: sílaba; aquisição da estrutura silábica; desempenho na escrita; ataques ramificados; conhecimento fonológico; sistema ortográfico; Português Europeu

\section{Introdução}

A aquisição da estrutura silábica tem sido alvo de diversos estudos em várias línguas do mundo ao longo dos anos, sendo o português uma delas (Amorim, 2014; Ávila, 2000; Freitas, 1997; Gálea, 2008; Ramalho, 2017; Ribas, 2004; entre outros). Apesar de o trabalho de investigação que tenta correlacionar a aquisição da estrutura silábica e o seu impacto na escrita de crianças nos seus primeiros anos de escolaridade (no qual se dá o primeiro contacto com o sistema escrito de uma língua materna) não ser abundante ${ }^{1}$, alguns estudos têm sido desenvolvidos nesse âmbito (Miranda, 2007; Santos, 2013; Veloso, 2003; entre outros).

Este estudo apresenta dois objetivos principais: por um lado, pretende avaliar o desempenho escrito de crianças do $2^{\circ}$ e $4^{\circ}$ ano (da área de Lisboa) em estreita relação com a ordem de aquisição da estrutura silábica, mais propriamente a análise dos grupos consonânticos não problemáticos (os ataques ramificados constituídos pelas sequências obstruinte+líquida.) e, por outro, confrontar os resultados obtidos na escrita com o que é referido na literatura sobre a aquisição dos ataques ramificados do Português Europeu (PE).

Este trabalho centrar-se-á em dois aspetos distintos: (i) identificar as formas não convencionais (FN-Cs $\left.{ }^{2}\right)$ que as crianças portuguesas apresentam na escrita de palavras com os grupos consonânticos referidos e (ii) analisar e perceber as motivações subjacentes a essas formas. Para efeitos do presente estudo foi utilizado o corpus online EFFE-On ${ }^{3}$.

\footnotetext{
${ }^{1}$ De um modo geral, os estudos sobre a aprendizagem da ortografia e da escrita são menos e mais recentes do que os estudos acerca da aquisição da componente fonológica e do próprio sistema de leitura da língua (Rodrigues, c.p). Sobre este assunto, consulte-se, por exemplo, Guimarães (2005), entre outros.

${ }^{2}$ Quando neste artigo nos referimos a formas não convencionais da escrita (FN-Cs), referimo-nos aos erros ou desvios que as crianças dão na escrita de palavras. São erros de representação gráfica das palavras, comuns nos primeiros anos do ensino básico.

${ }^{3}$ Rodrigues, C., Lourenço-Gomes, M. C., Alves, I., Janssen, M., Gomes, I. L. (2015): EFFE-On - Escreves como falas - Falas como escreves? (Online corpus of writing and speech of children in the early years of schooling), Lisboa: CLUL. ISLRN: 716-103-425-4829. Disponível em [http://alfclul.clul.ul.pt/teitok/effe/index.php, consultado entre 29 de julho e 6 de setembro de 2018].
} 


\section{A sílaba - percursos de aquisição e ortografia}

No que toca à estrutura fonológica e de acordo com um modelo multilinear, a sílaba é uma unidade de organização prosódica dos segmentos no sistema fonológico de uma língua (Gussenhoven \& Jacobs, 1998; Nespor \& Vogel, 1986/2007), uma vez que a «discussão do próprio status fonémico dos segmentos, em um determinado sistema, não pode ser desvinculado de uma consideração sobre a estrutura silábica» (Alves, 2017). Num modelo de ataque-rima (Selkirk, 1982/1984), as características gerais desta unidade em português são as seguintes ${ }^{4}$ : «(i) a sílaba do português tem estrutura binária, representada pelos constituintes ataque e rima, dos quais apenas a rima é obrigatória; (ii) a rima também tem estrutura binária, núcleo e coda (o núcleo é sempre uma vogal, e a coda é uma soante ou /S/) e (iii) o ataque compreende ao máximo dois segmentos, o segundo dos quais é uma soante não nasal» (Bisol, 2013 [1999]: 13 apud Alves, 2017: 133).

Fora do âmbito deste trabalho estão, portanto, sequências mais complexas, como, por exemplo, sequências heterossilábicas de $\mathrm{C}_{\mathrm{OCL}}+\mathrm{C}_{\mathrm{N}} \mathrm{em}$ "pneu"5. Desta forma, correspondem a ataques ramificados quatro combinações possíveis: oclusiva + vibrante $([\mathrm{pr}],[\mathrm{br}],[\mathrm{tr}],[\mathrm{dr}],[\mathrm{kr}] \mathrm{e}[\mathrm{gr}])$, oclusiva + lateral $([\mathrm{pl}],[\mathrm{bl}],[\mathrm{tl}]$, [kl] e [gl]), fricativa + vibrante ([fr] e [vr]) e fricativa + lateral ([fl]). Estas sequências consonânticas, que se organizam no domínio do ataque ramificado, obedecem a dois princípios fundamentais: ao Princípio da Sonoridade e à Condição de Dissemelhança (Mateus \& d'Andrade, 2000; Vigário \& Falé, 1993). Juntamente com o núcleo (e coda, caso exista), estes ataques ramificados formam uma sílaba mais natural ${ }^{6}$, tanto do ponto de vista percetivo e de produção como também da frequência destas estruturas numa língua como o português (Santos et al., 2014; Vigário et al., 2006). A figura seguinte ilustra a estrutura do modelo silábico de ataquerima:

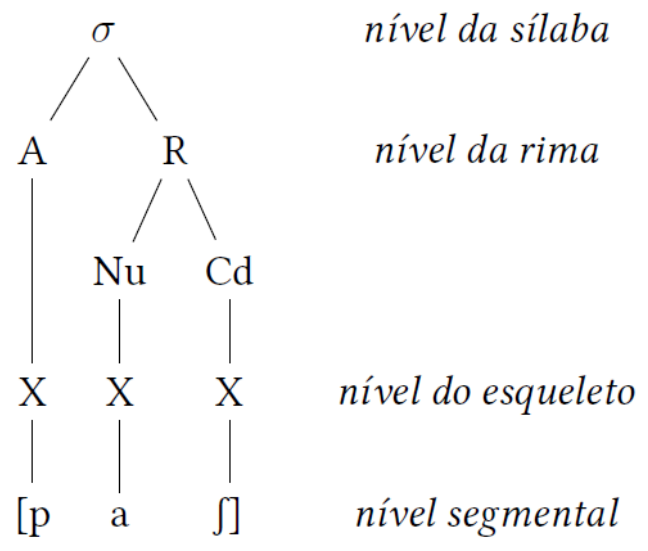

Figura 1 - Estrutura da sílaba no modelo de ataque-rima (Freitas, 2017: 73)

\footnotetext{
${ }^{4}$ Para a língua portuguesa, a definição que é apresentada para as características da sílaba é de carácter geral, existindo diferenças para as descrições assumidas para a variedade brasileira e portuguesa. Para uma definição mais alargada e pormenorizada sobre a sílaba no PE, consulte-se, por exemplo, Freitas (1997, 2001, 2003, 2016, 2017); Mateus et aliae. (2003) e Mateus \& d'Andrade (2000). Para considerações aprofundadas sobre a sílaba na variedade brasileira, consulte-se, por exemplo, Bisol (1996/1999), entre outros.

${ }^{5}$ A par de outros, isto é um exemplo de um grupo consonântico problemático, assunto que não será discutido neste artigo.

${ }^{6}$ Por comparação com as sequências formadas por grupos consonânticos problemáticos (cf. nota 5).
} 
Relativamente aos estudos sobre aquisição fonológica, a sílaba está presente nas primeiras produções espontâneas de crianças (Afonso \& Freitas, 2010; Ávila, 2000; Charrua, 2011; Freitas, 1997, 1998; Freitas \& Faria, 1999; Freitas \& Santos, 2001; Gálea, 2008; Miranda \& Silva, 2011; Ribas, 2004; entre outros).

Num modelo de aquisição top-down ${ }^{7}$, em que é o desenvolvimento silábico que restringe a emergência segmental (Freitas, 2003), «as crianças não começam por produzir sons isolados, pelo contrário, quando a comunicação com o adulto se estabelece através do uso de estruturas já identificadas como palavras, os sons assumem um formato silábico, que recupera alguma informação da palavra alvo. A sílaba é, assim, a primeira unidade linguística com constituência interna a ser usada pela criança no processo de aquisição de uma língua natural» (Freitas \& Santos, 2001: 59). A tabela abaixo apresenta a ordem de estabilização ${ }^{8}$ dos constituintes silábicos:

\begin{tabular}{ll|l}
\hline \hline Estádio 1 & Ataque não ramificado + Rima não ramificada: $\mathrm{CV} / \mathrm{V}$ \\
Estádio 2 & Ataque não ramificado + Rima ramificada: $(\mathrm{C}) \mathrm{VC}_{\text {fricativa }}$ \\
Estádio 3 & Núcleo ramificado: $(\mathrm{C}) \mathrm{VG} /(\mathrm{C}) \mathrm{VC}_{\text {líquida }}$ & Ataque ramificado $\mathrm{CCV}$ \\
Estádio 4 & Ataque ramificado: $\mathrm{CCV}$ & Núcleo ramificado $(\mathrm{C}) \mathrm{VC}_{\text {líquida }}$ \\
\hline \hline
\end{tabular}

Tabela 1 - Ordem de estabilização dos constituintes silábicos no PE (Freitas, 2017: 90).

No que respeita à aquisição do constituinte ataque temos: estádio I - ataque não ramificado (associado a oclusivas, a nasais e a vazio); estádio II - ataque não ramificado (associado a fricativas e a líquidas) e o estádio IV - ataque ramificado (Amorim, 2014; Freitas \& Santos, 2001: 60-61).

Segundo Santos (2013: 21-22), e na sequência de Freitas (1997, 2003) para o PE, são referidos os seguintes estádios para a aquisição de ataques ramificados: o estádio 0 corresponde a uma etapa em que palavras com grupos consonânticos não surgem como alvos possíveis; no estádio 1 o grupo consonântico é reduzido ao primeiro elemento $\left(\mathrm{C}_{1} \mathrm{C}_{2} \rightarrow \mathrm{C}_{1} \varnothing\right)$ ou substituído por um ataque vazio $\left(\mathrm{C}_{1} \mathrm{C}_{2} \rightarrow \emptyset \emptyset\right)$. Exemplos ${ }^{9}$ : <creme> - /'krعmi/ $\rightarrow$ ['ke] (Inês: 1;5.11), <flor> - /'flor/ $\rightarrow$ ['oli] (Inês: 1;9.19). Em Freitas (1997) coloca-se a hipótese de um estádio 2 , no qual o grupo consonântico é reduzido ao segundo elemento $\left(\mathrm{C}_{1} \mathrm{C}_{2} \rightarrow \emptyset \mathrm{C}_{2}\right)$, embora este estádio não se tenha manifestado, até ao momento, produtivo em PE (Amorim, 2014; Ramalho, 2017). Exemplo: <flores> - /'floríf/ $\rightarrow$ ['lolif] (Marta: 1;7.17). O estádio 3, em que os elementos do grupo consonântico são produzidos, compreende duas subfases: na primeira, os elementos do grupo consonântico estão associados a uma só posição do esqueleto, sendo encarados com um segmento complexo $\left(\mathrm{C}_{1} \mathrm{C}_{2}\right)$; na segunda, existem dados com uma vogal epentética entre as duas consoantes do grupo $\left(\mathrm{C}_{1} \mathrm{C}_{2} \rightarrow \mathrm{C}_{1} \mathrm{VC}_{2}\right)$ e outros dados conforme o alvo $\left(\mathrm{C}_{1} \mathrm{C}_{2}\right)$. Exemplos para este último caso: <cabra> - /'kabre/ a ser produzido tanto como ['kabire] ou ['kwabre] (Luís: 2;5.7). No estádio 4, as sequências são produzidas em conformidade com o alvo (Freitas, 1997, 2003).

O segundo segmento dos ataques ramificados em português, de acordo com as combinações que foram apresentadas atrás, é sempre uma consoante líquida alveolar, seja ela a vibrante [r] ou a lateral [1]. O rótico coronal $[r]$ «emerge em momentos distintos nos três constituintes silábicos a que pode pertencer» (Freitas \&

\footnotetext{
${ }^{7}$ Argumentando a favor do seguinte modelo, «não é porque a criança já é capaz de articular um dado som que ele surge em qualquer local da cadeia segmental: a emergência de um segmento só se dá quando o constituinte silábico que contém esse segmento já está disponível» (Freitas \& Santos, 2001: 67). No entanto, um avaliador anónimo chama a nossa atenção para o facto de haver estudos recentes que questionam esta análise, defendendo uma abordagem bottom-up ou até mesmo uma abordagem paralela.

${ }^{8}$ Existe, por outro lado, uma ordem de emergência dos constituintes silábicos que, segundo Freitas \& Santos (2001: 65), é: «Estádio I Ataque não ramificado e Núcleo não ramificado; Estádio II - Coda (Rima ramificada); Estádio III - Núcleo ramificado e, por fim, Estádio IV - Ataque Ramificado».

${ }^{9}$ Todos os exemplos que demonstram os estádios de aquisição do ataque ramificado em PE são retirados de Santos (2013: 21-22).
} 
Santos, 2001: 67), nomeadamente: em ataque não ramificado, em coda e, por fim, em ataque ramificado. Esta ordem de emergência do segmento [ $\mathrm{f}$ 《 «regista-se também para os outros segmentos que podem ocorrer no Português tanto em Ataque como em Coda, a saber, as fricativas palatais $\left[\int, 3\right]$ e a lateral alveolar ([1] em Ataque e [1] em Coda)» (ibid.).

A fronteira entre a fonologia e o sistema ortográfico de uma língua é clara e é por esta razão que os estudos que equacionam o impacto da primeira área sobre a segunda (ou vice-versa) podem tornar os dados de validade discutível. O conhecimento fonológico é implícito e intuitivo enquanto o conhecimento ortográfico é explícito e aprendido. Apesar de estas áreas serem distintas, elas interrelacionam-se, pois «o sistema fonológico e o sistema gráfico de uma língua são dois sistemas distintos, mas as relações entre eles são estreitas e íntimas» (Gleason, 1961, passim). Só depois de conhecermos a ordem de aquisição das estruturas fonológicas (a sílaba e os segmentos que a preenchem) é que podemos correlacionar esta área com os dados da escrita de uma língua. Só assim conseguiremos estabelecer uma ponte suficientemente estável e convincente entre os dois sistemas, pois «Children's spelling also provide an excelente window into their knowledge of phonology and orthography» (Treiman, 1998: 291 apud Santos et al. 2014: 411).

$\mathrm{O}$ interesse em estudar os ataques ramificados na escrita advém do facto de o ataque ramificado constituir a última estrutura a ser adquirida pelas crianças portuguesas nos estudos disponíveis e poderá não estar estabilizado à entrada do ensino primário (Ramalho, 2017; Santos et al. 2014 mencionam dados do TFFALPE de Mendes et al., 2009/2013). De que forma poderão as crianças lidar com este facto na aprendizagem da ortografia? Esta é uma pergunta que aqui debatemos, não obstante as questões de investigação específicas em discussão neste estudo.

Os dados de escrita que as crianças produzem poderão ser uma pista linguística para o conhecimento fonológico, pois Pinto 1997: 10 apud Santos et al., 2014: 411 «refere a importância dos erros ortográficos como material empírico de acesso ao modo como o conhecimento ortográfico se vai consolidando, sendo aqueles claramente formatados por critérios linguísticos, registando-se correlações entre estruturas do oral e registos ortográficos infantis».

Aprender a ler e a escrever não é um processo natural como o de adquirir uma língua, mas «um dos fatores que pode condicionar a forma das primeiras palavras escritas é o nível de desenvolvimento fonológico em que a criança se encontra» (Santos et al., 2014: 412). Quando começam a aprender a escrever é, em certa medida, expectável que as crianças produzam erros. O interesse dos estudos sobre a aprendizagem da escrita em crianças é perceber exatamente quais poderão ser as motivações por detrás dessas FN-Cs. Há autores (cf. Miranda \& Matzenauer, 2010; Sousa, 1999; entre outros) que afirmam que os erros que as crianças produzem na escrita poderão provir de motivações fonéticas, facto que também é corroborado por Pinto (1997: 8), que afirma que «a influência fonética pode considerar-se mais prevalente em português do que nas outras duas línguas ${ }^{10}$, nas quais a ortografia é mais complexa». Outros afirmam ainda que as dificuldades que as crianças encontram em registar certas estruturas silábicas pode dever-se à complexidade destas (cf. Guimarães, 2005; Miranda, 2007; entre outros).

Nem todas as línguas têm o mesmo grau de transparência fonémica na escrita. O espanhol, por exemplo, mantém uma correspondência biunívoca entre fonemas e grafemas; já o sistema ortográfico do português encontra-se numa posição intermédia face a outras línguas (cf. figura 2). Existem sons do português que têm uma relação direta com a grafia ${ }^{11}$, como é o caso, por exemplo, das consoantes $[\mathrm{p}],[\mathrm{b}],[\mathrm{t}],[\mathrm{d}],[\mathrm{f}],[\mathrm{v}],[K] \mathrm{e}$ [n], que correspondem sempre ao mesmo grafema. O mesmo não acontece com as restantes consoantes e vogais desta língua. Veja-se a figura abaixo sobre a posição de algumas línguas face à escala de classificação apresentada.

\footnotetext{
${ }^{10}$ Neste estudo, estava em destaque, para além do português, o francês e o inglês.

${ }^{11}$ Não estamos a considerar variantes alofónicas nem fenómenos dialetais (como por exemplo, o betacismo).
} 


$\left.\left.\left.\sum \begin{array}{c}\text { Finlandês } \\ \text { Italiano } \\ \text { Espanhol }\end{array}\right\rangle \begin{array}{c}\text { Grego } \\ \text { Alemão }\end{array} \gg \begin{array}{l}\text { Português } \\ \text { Holandês }\end{array}\right\rangle \begin{array}{c}\text { Islandês } \\ \text { Norueguês }\end{array}\right\rangle$ Sueco $\left.\gg \geqslant \begin{array}{c}\text { Francês } \\ \text { Dinamarquês }\end{array}\right\rangle$ Inglês $\rangle$

Figura 2 - Escala de classificação para sistemas ortográficos de línguas europeias relativamente ao grau de opacidade, segundo Seymour, 1997 apud Vale, 1999. Figura retirada de Santos, R. (2013: 28).

Pela análise desta escala, verifica-se que o inglês é a língua mais opaca, revelando-se esta uma língua difícil para estudar a correlação da fonologia e da ortografia. A correlação sobre o cruzamentro do sistema fonológico e ortográfico torna-se, pois, mais acessível no PE, pois este «pertence ao conjunto de línguas em que prevalece a transparência fonémica da ortografia» (Veloso, 2005: 59 apud Lopes, 2011: 18).

Quanto aos erros que as crianças apresentam na escrita, remete-se, neste estudo, apenas para os erros de vocabulário. Veja-se o quadro seguinte com a proposta de categorização dos erros ortográficos no português de Mateus (2003):

\begin{tabular}{|c|c|}
\hline Categorias & Subcategoria \\
\hline $\begin{array}{l}\text { Regras } \\
\text { gramaticais }\end{array}$ & $\begin{array}{l}\text { Formação do plural, superlativo absoluto simples, numerais, verbos, conjunções, } \\
\text { locuções, interjeições, composição e derivação; }\end{array}$ \\
\hline $\begin{array}{l}\text { Erros de } \\
\text { vocabulário }\end{array}$ & $\begin{array}{l}\text { Ortografia do uso, confusão de letras, adição de letras, omissão de letras, homógrafas, } \\
\text { homófonas, composição e ortografia fonética e disfonética, adição de vogais, adição de } \\
\text { consoantes, queda de vogais, queda de consoantes, substituição de vogais e de } \\
\text { consoantes, metátese; }\end{array}$ \\
\hline $\begin{array}{l}\text { Acentuação - } \\
\text { Corte anormal - } \\
\text { Aglutinação. }\end{array}$ & Omissão de acentos, adição de acentos; divisão silábica; \\
\hline
\end{tabular}

Tabela 2 - Classificação dos erros ortográficos segundo Mateus (2003: 168) apud Leitão (2016: 25) ${ }^{12}$.

Com base nos objetivos do presente estudo - avaliar o desempenho escrito de crianças do $2^{\circ}$ e $4^{\circ}$ ano na relação com a ordem de aquisição dos ataques ramificados constituídos pelas sequências obstruinte+líquida e confrontar os resultados obtidos na escrita com o que é referido na literatura sobre a aquisição dos ataques ramificados do PE -, enunciam-se as três questões de investigação subjacentes a este estudo:

1. A que estratégias recorrem as crianças para resolver, na escrita, a grafia dos ataques ramificados?

2. Qual a frequência de utilização das diferentes estratégias de grafar os ataques ramificados no $2^{\circ}$ e $4^{\circ}$ ano de escolaridade?

\footnotetext{
${ }^{12}$ Segundo a mesma fonte, outras propostas poderão ser encontradas em Pinto (1998); Sousa (1999); Barbeiro, Batista \& Viana (2008); Santos (2013); entre outros.
} 
3. A ordem de aquisição da estrutura silábica condiciona o encontro de formas ortográficas não convencionais (FN-Cs) nessas crianças?

\section{Metodologia}

\subsection{Corpus, amostra e procedimento}

O corpus "EFFE-On: Escreves como falas - Falas como escreves?" é constituído por dados recolhidos em várias zonas do país (nomeadamente em Lisboa e Porto ${ }^{13}$ ) em dois anos de escolaridade distintos $-2^{\circ}$ e $4^{\circ}$ ano. O corpus em causa foi criado no sistema CTEITOK (Janssen, 2014) para ser disponibilizado online (Lourenço-Gomes, Rodrigues \& Alves, 2015). Os objetivos da criação deste banco de dados prendem-se, entre outros propósitos, com a necessidade de (i) verificar se alguns erros ortográficos em textos do primeiro ciclo de escolaridade são motivados pela fala e (ii) reunir produções orais e escritas que justifiquem as respetivas FN-Cs. A recolha de dados para este corpus consistiu na realização de duas tarefas: (i) narração escrita de uma história evocada por sequências de imagens sem palavras e (ii) descrição escrita detalhada de uma imagem repleta de figuras que motivam o uso dos diferentes segmentos fonológicos do PE. Em muitos estudos de carácter experimental, sabe-se que há dificuldade na recolha de dados escritos espontâneos ou semiespontâneos junto da população infantil e, por isso, não há muito material disponível para os estudos sobre as línguas. Os bancos de dados, como a plataforma EFFE-On, vêm permitir que professores, investigadores, alunos, etc., acedam mais facilmente a dados para diversos tipos de estudos.

Este artigo corresponde a um estudo longitudinal, a partir da análise do desempenho escrito de duas turmas, em dois anos de escolaridade distintos. As informações recolhidas correspondem a dados das mesmas crianças, no $2^{\circ}$ e no $4^{\circ}$ ano do ensino básico, na cidade de Lisboa. As duas turmas de $2^{\circ}$ e $4^{\circ}$ ano contam com aproximadamente 50 alunos (cf. tabela 3). Assim, é através da análise dos dados da plataforma EFFE-On que, neste contexto, poderemos descrever os contornos da relação entre o conhecimento fonológico e o sistema ortográfico das crianças que frequentam os primeiros anos do ensino básico, contribuindo, desta forma, para os estudos que correlacionam a aquisição da sílaba com a escrita de uma língua.

\begin{tabular}{|l|l|l|l|l|l|l|}
\hline $\begin{array}{l}\text { Anoe } \\
\text { Turma }\end{array}$ & Crianças & Escolas & Sexos & Textos & Gravações & Idades \\
\hline 2A e 2B & 48 & $\begin{array}{l}\text { CM } \\
\text { privada }\end{array}$ & $\begin{array}{l}\text { M-23 } \\
\text { F-25 }\end{array}$ & 96 & 58 & 7 \\
\hline 4A e 4B & 54 & $\begin{array}{l}\text { CM } \\
\text { privada }\end{array}$ & $\begin{array}{l}\text { M-31 } \\
\text { F-23 }\end{array}$ & 108 & - & 9 \\
\hline
\end{tabular}

Tabela 3 - Dados de Lisboa

(tabela retirada de Alves et al. (2015: 28)

\footnotetext{
${ }^{13}$ Muito recentemente, este corpus tem sido alargado a outras zonas de Portugal, como Chaves, Bragança, Viseu e Elvas.
} 
A recolha dos dados deste trabalho organizou-se em quatro etapas: (i) levantamento e registo individual dos dados de escrita ${ }^{14}$; (ii) agrupamento dos resultados em gráficos por modo de articulação e por ano de escolaridade (cf. gráficos 1 a 5) e, por fim, (iii) apresentação de gráficos que demonstram as percentagens correspondentes a cada estratégia de resolução, na escrita, dos ataques ramificados adotada pelas crianças nos dois anos de escolaridade (cf. gráfico 6 e 7). Para além dos gráficos, apresenta-se uma tabela (5) com alguns exemplos de FN-Cs representativos de todos os grupos consonânticos.

Os dados nas categorias que se encontram na tabela abaixo não foram considerados neste estudo.

\begin{tabular}{|c|l|}
\hline $\begin{array}{c}\text { Presença de pseudopalavras (e/ou } \\
\text { invenção de palavras) }\end{array}$ & Exemplo: Urclatonsarex \\
\hline Onomatopeias & Exemplo: trim \\
\hline Separação de vocábulos & $\begin{array}{l}\text { Exemplo: } \\
\text { abra_cadabra }\end{array}$ \\
\hline $\begin{array}{c}\text { Colocação de ataques ramificados } \\
\text { onde eles não existem }\end{array}$ & Exemplo: des_clopa \\
\hline
\end{tabular}

Tabela 4 - Dados que não foram considerados no presente estudo.

\section{Apresentação e descrição dos resultados}

Nesta secção, são expostos os dados obtidos a partir da amostra escolhida no corpus. O gráfico que se segue apresenta os valores percentuais do ataque ramificado constituído por oclusiva + vibrante dos $2^{\circ}$ e $4^{\circ}$ ano de escolaridade. Com um total de 580 formas encontradas no $2^{\circ}$ ano, verificou-se que, destas, $534(92,1 \%)$ foram realizadas conforme o alvo e apenas $46(7,9 \%)$ como FN-Cs. Para o $4^{\circ}$ ano, em 1442 formas totais, $1424(98,8 \%)$ foram executadas conforme o alvo e, somente, $18(1,2 \%)$ como FN-Cs.

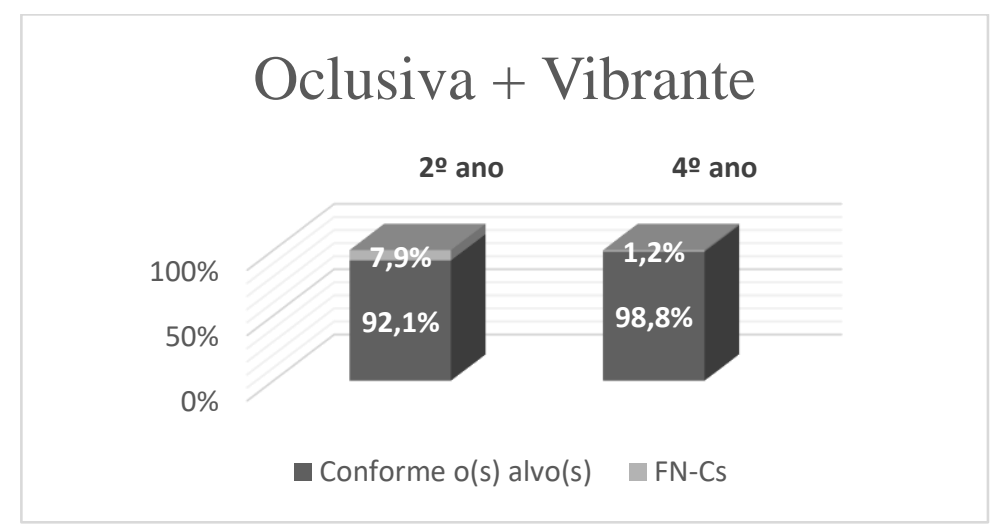

Gráfico 1 - Resultados por modo de articulação (oclusiva+vibrante) nos dois anos de escolaridade.

\footnotetext{
${ }^{14}$ Os parâmetros de pesquisa utilizados para o registo dos dados individuais de cada grupo consonântico foram os seguintes: ano de escolaridade (p. ex., $2^{\circ}$ ano), cidade (Lisboa), forma normalizada/alvo (p. ex., [pr]), total de resultados, resultados conforme a forma normalizada/o alvo, número de formas não convencionais (FN-Cs) e, por fim, registo de alguns exemplos das FN-Cs.
} 
O Gráfico 2 apresenta os resultados para o ataque ramificado composto por oclusiva+lateral. Nesta construção, obtiveram-se 27 formas, das quais 21 (77,8\%) correspondem ao alvo e $6(22,2 \%)$ a FN-Cs, nos dados do $2^{\circ}$ ano. Nas crianças do $4^{\circ}$ ano, houve um total de 85 formas: $84(98,9 \%)$ conforme o alvo e $1(1,2 \%)$ como FN-Cs.

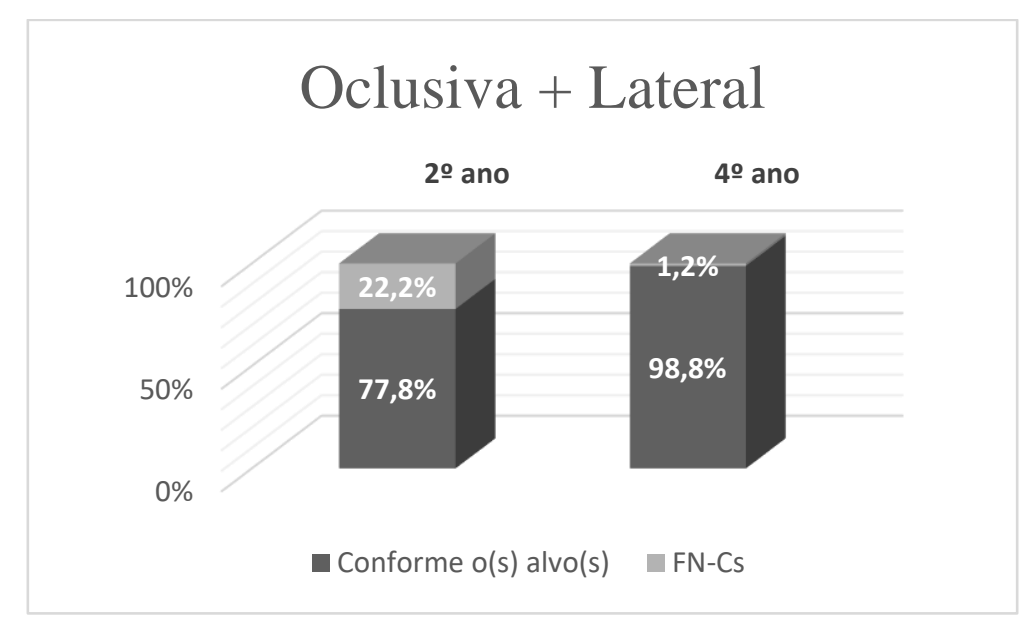

Gráfico 2 - Resultados por modo de articulação (oclusiva +lateral) nos dois anos de escolaridade.

No que toca aos dados dos ataques ramificados fricativa+vibrante, foram atestadas 37 formas totais para o $2^{\circ}$ ano, nas quais $28(75,7 \%)$ correspondem à forma alvo e $9(24,3 \%)$ à FN-Cs. Nas crianças do $4^{\circ}$ ano, foram atestadas 65 formas, em que as mesmas correspondiam ao alvo, não tendo sido encontrada nenhuma FN-Cs deste grupo consonântico. O gráfico abaixo dá conta destes resultados:

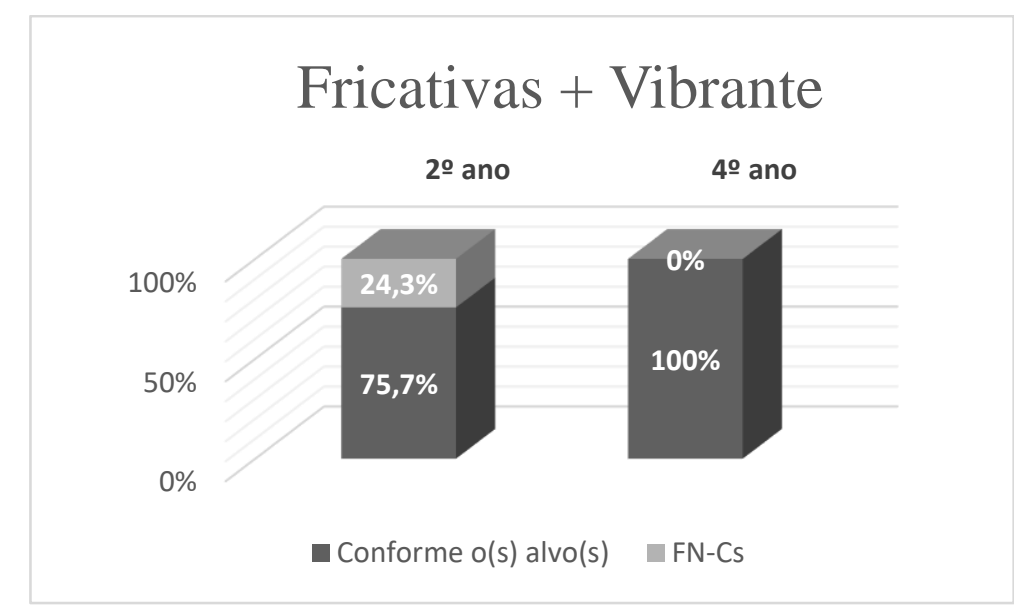

Gráfico 3 - Resultados por modo de articulação (fricativa +vibrante) nos dois anos de escolaridade. 
Em relação aos dados do ataque ramificado fricativa+lateral, o Gráfico 4 indica que, das 25 formas encontradas no $2^{\circ}$ ano, $15(60 \%)$ correspondem à forma alvo e $10(40 \%)$ correspondem às FN-Cs. Relativamente aos dados do $4^{\circ}$ ano, foram encontradas 61 formas, das quais $55(90,2 \%)$ dizem respeito ao alvo e $6(9,8 \%)$ a FN-Cs.

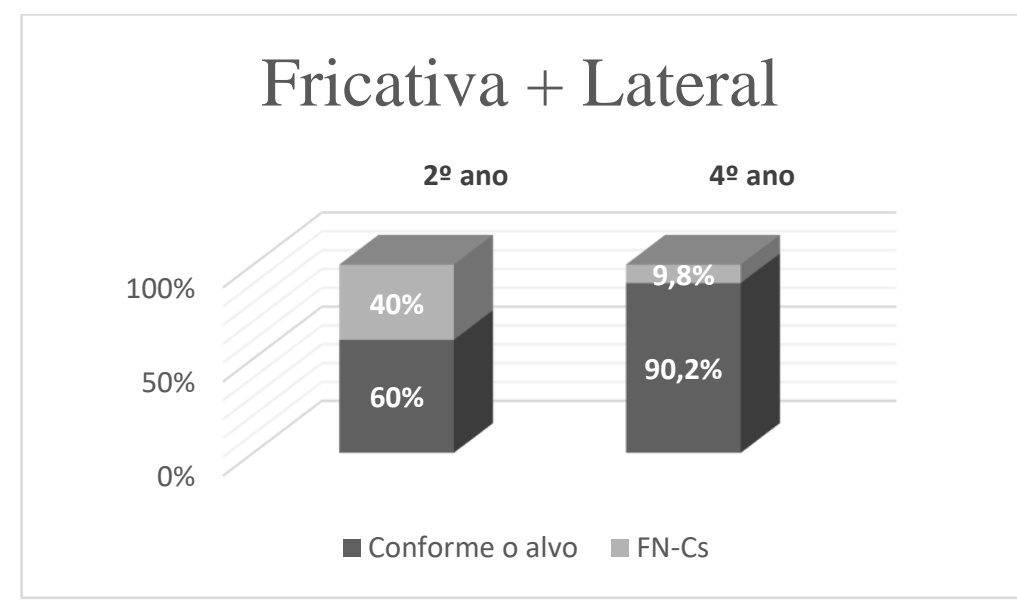

Gráfico 4 - Resultados por modo de articulação (fricativa +lateral) nos dois anos de escolaridade.

Após o levantamento dos dados nas duas turmas apontadas, procedeu-se à compilação dos resultados dos diferentes ataques ramificados num gráfico por ano de escolaridade. Assim, para o $2^{\circ}$ ano, foram encontradas $598(89,4 \%)$ formas convencionais e $71(10,6 \%)$ FN-Cs, o que resulta num total de 669 formas. No $4^{\circ}$ ano, encontrou-se um total de 1653 palavras com ataques ramificados, dividindo-se este número em 1628 (98,5\%) de acordo com o alvo e 25 (1,5\%) de FN-Cs. Veja-se o gráfico seguinte:

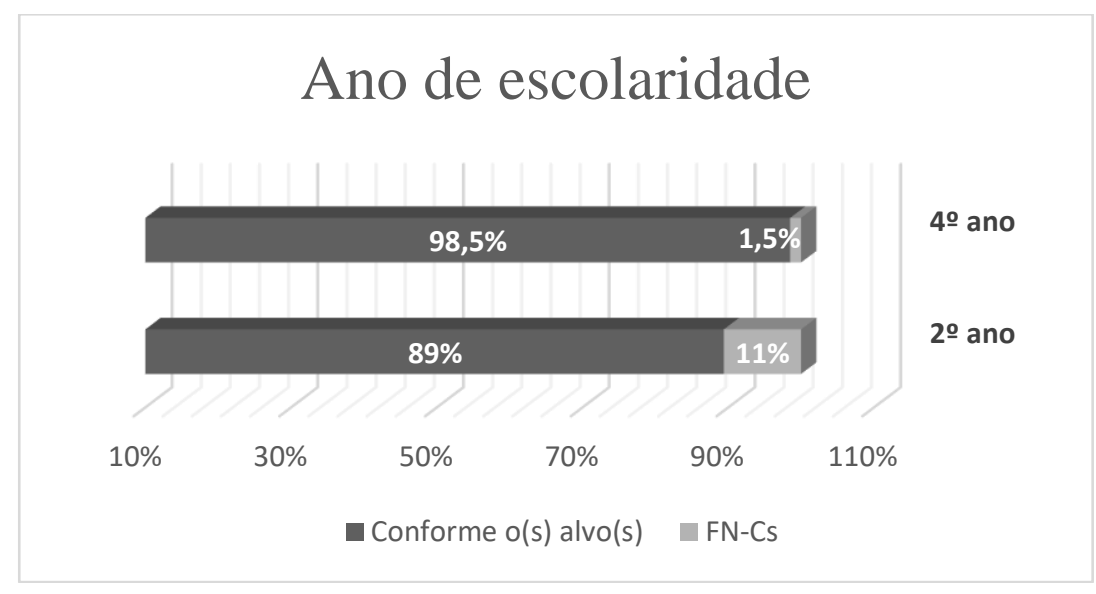

Gráfico 5 - Resultados agregados por ano escolar. 
A partir da análise da realização de ataques ramificados na ortografia, analisaram-se as estratégias adotadas pelas crianças na escrita de palavras com os grupos consonânticos aqui em discussão. No que se refere aos dados de resolução dos ataques ramificados, o gráfico que se segue dá conta das estratégias adotadas por alunos do $2^{\circ}$ ano de escolaridade: 39 (54,9\%) casos de epêntese de vogal; 16 (22,5\%) de elisão da segunda consoante do ataque ramificado $\left(\mathrm{C}_{1} \mathrm{C}_{2} \mathrm{~V} \rightarrow \mathrm{C}_{1} \emptyset \mathrm{V}\right) ; 13(18,3 \%)$ de metátese ${ }^{15}$ e, por último, 3 $(4,2 \%)$ de outras estratégias.

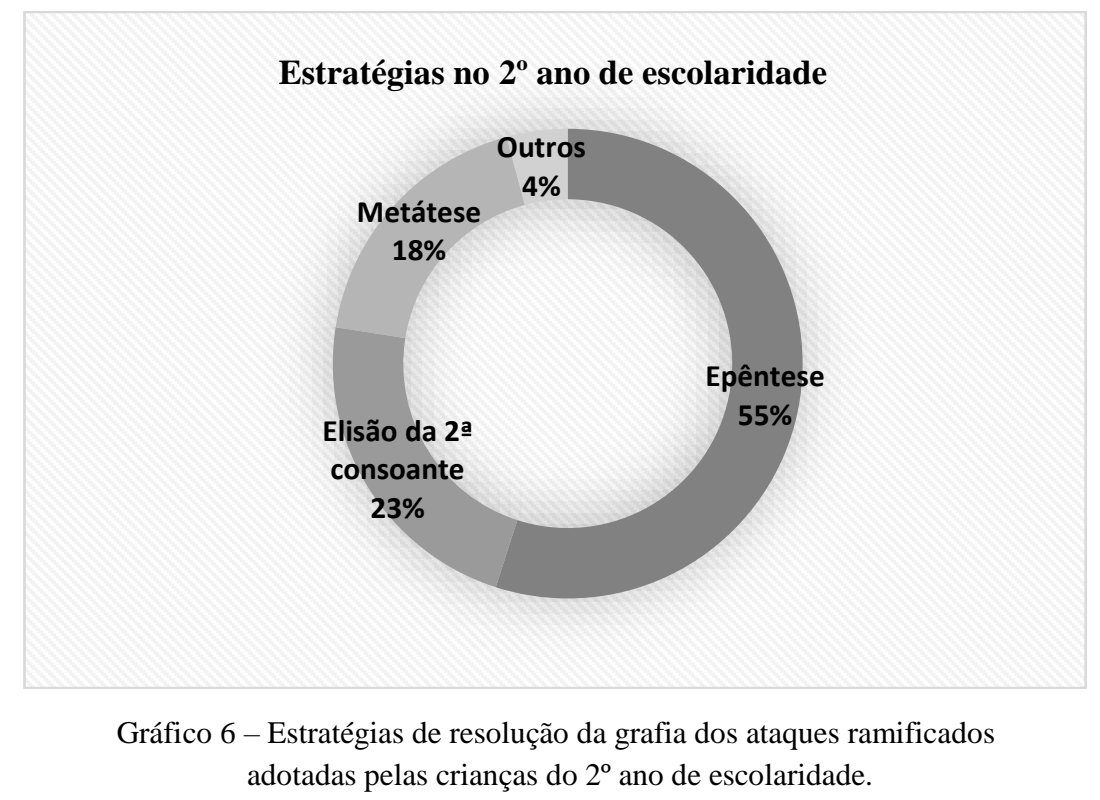

Nos dados dos alunos do $4^{\circ}$ ano, verifica-se o uso de epêntese de vogal em 9 palavras (36\%); o uso da elisão da segunda consoante em 7 palavras (28\%) e, por fim, o uso da metátese em 9 palavras $(36 \%)$.

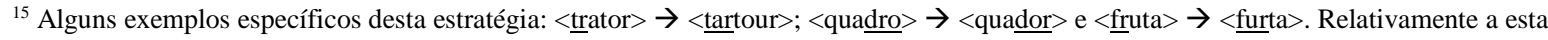
estratégia é importante referir que, nos dados deste artigo e para os dois anos de escolaridade apontados, não foram encontradas metáteses com o segmento consonântico lateral [1].
} 


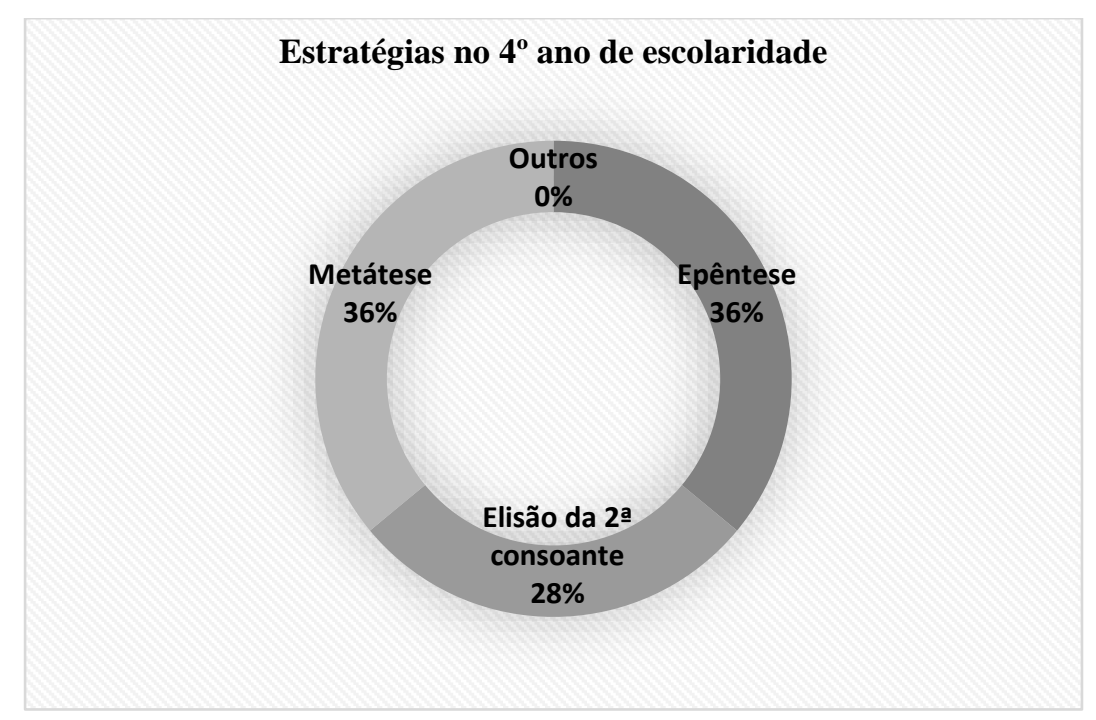

Gráfico 7 - Estratégias de resolução da grafia dos ataques ramificados adotadas pelas crianças do $4^{\circ}$ ano de escolaridade.

Apresenta-se abaixo uma tabela com alguns exemplos de $\mathrm{FN}-\mathrm{Cs}$ produzidas na escrita das crianças.

\begin{tabular}{|c|c|c|c|}
\hline $\begin{array}{l}\text { Ano de escolaridade: } \\
2^{\circ} \text { ano do ensino básico } \\
\text { (Lisboa). }\end{array}$ & & $\begin{array}{l}\text { Ano de escolaridade: } \\
4^{\circ} \text { ano do ensino básico } \\
\text { (Lisboa). }\end{array}$ & \\
\hline Alvos: & FN-Cs: & Alvos: & FN-Cs: \\
\hline <aproximou-se> & <aperosimosse $>$ & <prateleira> & $\langle$ parteleira $>$ \\
\hline$\langle\underline{\text { bruxas }>}$ & $<$ borchas $>$ & <brincar> & $<$ bincar $>$ \\
\hline$<$ trator $>$ & $<$ tartour $>$ & $<\underline{\text { tremenda}>}$ & $<$ termenda $>$ \\
\hline 〈pedras> & $<$ pederas $>$ & & \\
\hline <crescer> & <cexere> & & \\
\hline <igreja> & <igaija> & & \\
\hline$<$ planta $>$ & $<$ pelanta $>$ & & \\
\hline <claro> & <quelaro> & <clarinho> & <quelarinho> \\
\hline
\end{tabular}




\begin{tabular}{|c|c|c|c|}
\hline <globo> & <gelobo > & & \\
\hline$<\underline{\text { frigorífico }>}$ & $\begin{array}{l}<\text { ferígorifico>, } \\
<\text { figorifico }>\end{array}$ & & \\
\hline$<$ livros $>$ & $<$ livoros $>$, <livors $>$ & & \\
\hline <aflitinho> & $<$ afelitinho > & <conflito> & $\langle$ confelito $>$ \\
\hline
\end{tabular}

Tabela 5 - Exemplos de FN-Cs na escrita de crianças, independentemente da respetiva frequência, representativo de todos os grupos consonânticos em estudo.

A tabela (5) que está exposta é meramente exemplificativa. É importante salientar que, mesmo para os casos em que o ataque ramificado foi corretamente produzido na escrita das crianças, isso não significa que a palavra esteja ortograficamente bem escrita. Existem palavras que ao nível da escrita não estão totalmente corretas, mas em que se verifica a ocorrência de ataques ramificados (um exemplo retirado do corpus: para o alvo [pr], temos a palavra alvo <prateleiras>, em que uma criança escreve <pratlairas>, correspondendo ao alvo [pr], mas errando na mesma a escrita da palavra na sua globalidade).

\section{Discussão dos resultados}

A análise dos resultados permite-nos observar que existe uma maior percentagem de FN-Cs no grupo consonântico das fricativa +lateral ( $2^{\circ}$ ano $-40 \% ; 4^{\circ}$ ano $\left.-9,8 \%\right)$, seguindo-se os grupos consonânticos das fricativas+vibrante $\left(2^{\circ}\right.$ ano $-24,3 \%$; sem resultados no $4^{\circ}$ ano), oclusiva + lateral $\left(2^{\circ}\right.$ ano $-22,2 \% ; 4^{\circ}$ ano $1,2 \%)$ e, por fim, oclusiva+vibrante $\left(2^{\circ}\right.$ ano $-7,9 \% ; 4^{\circ}$ ano $\left.-1,2 \%\right)$. Portanto, é o grupo consonântico fricativa+líquida que apresenta uma maior percentagem de $\mathrm{FN}-\mathrm{Cs}$, em contraste com o grupo consonântico oclusiva+líquida. Assim, podemos ter uma escala de sucesso na representação de ataques ramificados: oclusiva+vibrante > oclusiva+lateral $\gg$ fricativa+vibrante $\gg$ fricativa+lateral), dados que vão ao encontro dos que foram encontrados em Santos (2013).

Os erros que as crianças apresentam na escrita podem ser traduzidos no tipo de estratégias que essas mesmas crianças usam para resolver as dificuldades na representação de sílabas complexas (Sousa, 1999 apud Santos, 2013). No contexto deste artigo, e respondendo à primeira pergunta de investigação (A que estratégias recorrem as crianças para resolver na escrita a grafia dos ataques ramificados?), podemos referir que as crianças resolvem os ataques ramificados na escrita através da introdução de uma vogal, simplificando sílabas CCV(C) num formato silábico CV.CV. As vogais introduzidas na escrita por estas crianças são essencialmente três: $\mathrm{o}\langle\mathrm{e}\rangle,\langle\mathrm{o}\rangle \mathrm{e}\langle\mathrm{u}\rangle^{16}$. Porém, para além de usarem a epêntese de uma vogal para resolver a complexidade dos ataques ramificados, as crianças também recorrem a outras estratégias de resolução dos mesmos, como é o caso da elisão da segunda consoante do ataque ramificado $\left(\mathrm{C}_{1} \mathrm{C}_{2} \mathrm{~V} \rightarrow \mathrm{C}_{1} \emptyset \mathrm{V}\right)$ e a realização de metátese ${ }^{17}\left(\mathrm{C}_{1} \mathrm{C}_{2} \mathrm{~V} \rightarrow \mathrm{C}_{1} \emptyset \mathrm{VC}_{2}\right)$. No que toca ao fenómeno de metátese (com as crianças a preferirem codas preenchidas a ataques ramificados), este encontra motivações nos dados da aquisição. Sabe-se que as codas preenchidas são adquiridas antes dos ataques ramificados (cf. tabela 1). Sintetizando: podemos afirmar que

\footnotetext{
16 Apesar de não termos chegado a avaliar, no contexto deste artigo, quais destas três vogais é a mais frequentemente utilizada na epêntese, sabe-se que a vogal <e> ([i]) é um preenchedor prosódico no PE (Santos, 2013). Ver, também, Mateus \& d'Andrade (2000).

${ }^{17}$ No que toca a esta estratégia, foi-nos apontado a hipótese de a sílaba resultante poder ser $C_{1}$ V.C $C_{2}$ (Vigário, c.p). Não é de descartar; no entanto, não é esta a posição que aqui tomamos.
} 
são três as estratégias preferidas pelas crianças para resolver na escrita os ataques ramificados: (i) a epêntese de vogal, (ii) a elisão da segunda consoante do ataque ramificado e (iii) a metátese. Estes resultados vão ao encontro dos dados encontrados em Santos (2013).

De acordo com os gráficos referentes às estratégias de resolução da escrita dos ataques ramificados, e estabelecendo uma correspondência com a segunda pergunta de investigação (Qual a frequência de utilização das diferentes estratégias de grafar os ataques ramificados no $2^{\circ}$ e $4^{\circ}$ ano de escolaridade?), constata-se que a estratégia mais usada pelas crianças do $2^{\circ}$ ano de escolaridade é a epêntese de vogal (54,9\%). De seguida é a elisão da segunda consoante do ataque ramificado $(22,5 \%)$ e, por último, a metátese $(18,3 \%)$. A percentagem (4\%) associada a «Outros» corresponde a FN-Cs em que não se percebe ao certo que estratégia é que a criança está a utilizar, como nos casos de 〈zebra $\rangle \rightarrow\langle$ zeber $\rangle$; 〈livros $\rangle \rightarrow\langle$ livors $\rangle$ ou $\langle$ transformou $\rangle \rightarrow$ <estaforbo>. Neste último exemplo, a FN-Cs usada afasta-se bastante da palavra alvo ${ }^{18}$.

Quanto aos dados do $4^{\circ}$ ano de escolaridade, observa-se que ambas as estratégias de epêntese e de metátese são utilizadas de forma igual (com percentagens iguais - 36\%). Nota-se, aqui, que as crianças preferem de igual forma ambas as estratégias. Quanto à elisão da segunda consoante do ataque ramificado, ela tem uma percentagem de $28 \%$. Estabelecendo uma comparação entre os dados dos dois anos de escolaridade, observa-se um decréscimo na utilização de epêntese de vogal (de 55\% decresce para 36\%) e um aumento da elisão da segunda consoante do ataque ramificado (de 23\% aumenta para 28\%) e da metátese (aumentado $18 \%$ para $36 \%$ ). Conclui-se, então, que a frequência de utilização de estratégias para resolver, na escrita, os ataques ramificados não é a mesma nos dois anos de escolaridade analisados. É importante realçar que, apesar das percentagens apontadas neste estudo não mostrarem claramente, o número de FN-Cs decresce drasticamente do $2^{\circ}$ ano para o $4^{\circ}$ ano. No $4^{\circ}$ ano quase não existem produções de FN-Cs, o que pode resultar numa estatística insuficiente para os resultados deste ano de escolaridade. Não obstante, estes resultados vão, em parte, ao encontro dos que foram obtidos em Santos (2013: 63, 74). Apesar de esta autora utilizar dados de escrita do $1^{\circ}$ ano de escolaridade, o paralelismo é plausível. Confira-se os gráficos abaixo.

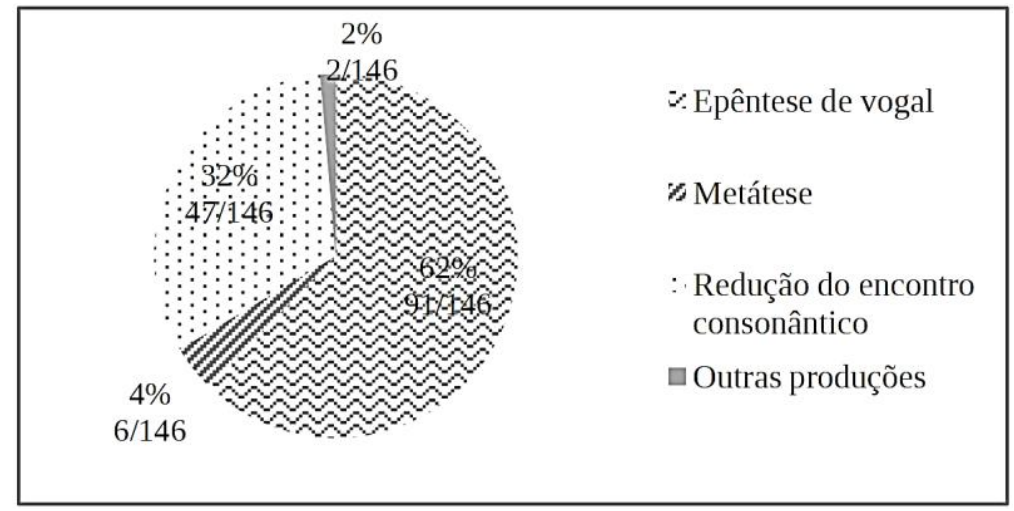

Gráfico 8 - Frequência dos erros de produção de escrita de Ataques ramificados, no $1^{\circ}$ ano de escolaridade (retirado diretamente de Santos (2013: 63)).

Comparando estes dados com os de Santos (2013: 63), observa-se que a epêntese de vogal é a estratégia mais utilizada nas crianças do $1^{\circ}$ e do $2^{\circ}$ ano de escolaridade (62\% e $55 \%$, respetivamente). A segunda estratégia mais utilizada pelas crianças do $1^{\circ}$ e $2^{\circ}$ ano de escolaridade é a de redução do encontro consonântico

\footnotetext{
${ }^{18}$ Neste estudo, não foram encontrados erros do tipo «grafias homófonas» (cf. Santos, 2013: 97).
} 
(ou elisão da segunda consoante do ataque ramificado; $32 \%$ e $23 \%$, respetivamente). A metátese, no $1^{\circ}$ e $2^{\circ}$ ano de escolaridade, é a estratégia menos usada (4\% e 18\%, respetivamente).

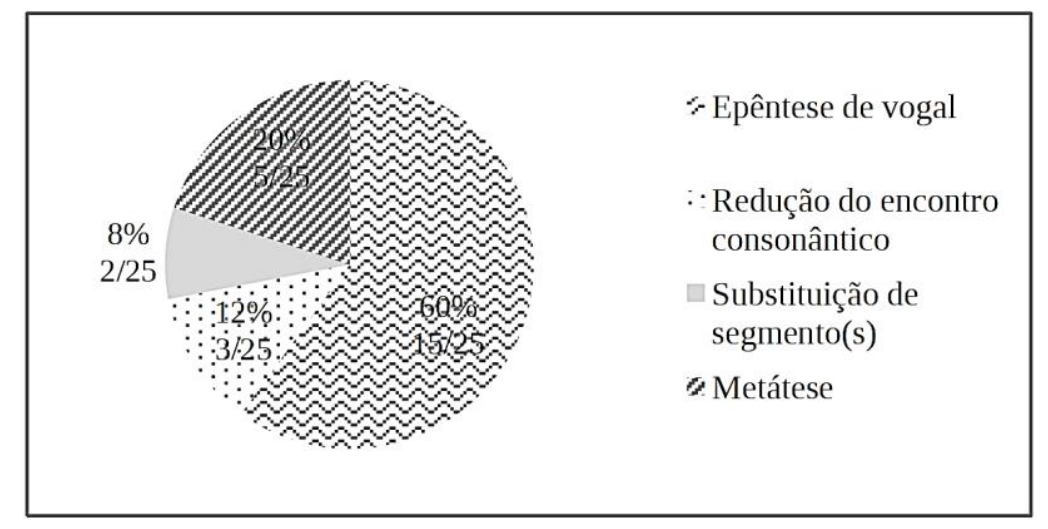

Gráfico 9 - Frequência dos erros de produção de escrita de Ataques ramificados, no $4^{\circ}$ ano de escolaridade (retirado diretamente de Santos (2013: 74)).

Em suma, observa-se que a epêntese de vogal em Santos (2013: 74), apesar de sofrer um ligeiro decréscimo (62\% para 60\%), continua a ser a estratégia preferida pelas crianças do $4^{\circ}$ ano de escolaridade. Nos dados deste artigo, o uso de epêntese de vogal como estratégia de resolução dos ataques ramificados no $4^{\circ}$ ano também decresce, mas de uma forma mais expressiva (de 55\% para 36\%). A redução do encontro consonântico para os dados do $4^{\circ}$ ano de escolaridade em Santos (2013) também decresce (de 32\% para 12\%). Neste artigo, para os dados do $4^{\circ}$ ano, a elisão da segunda consoante do ataque ramificado é uma estratégia que aumenta (de 18\% para 36\%) face a Santos (2013). Quanto ao uso da metátese no $4^{\circ}$ ano, ela aumenta tanto nos dados do estudo de Santos (2013) como neste artigo: no $4^{\circ}$ ano de escolaridade regista $36 \%$ face ao $2^{\circ}$ ano (18\%) e no estudo de Santos (2013) regista $20 \%$ face ao $1^{\circ}$ ano $(4 \%)$.

A terceira pergunta de investigação ( $A$ ordem de aquisição da estrutura silábica condiciona o encontro de formas ortográficas não convencionais ( $F N-C s$ ) nessas crianças?) remete-nos diretamente para o debate entre a relação do sistema fonológico e o sistema ortográfico de uma língua. Como foi veiculado na secção 2 , apesar de o sistema fonológico e ortográfico de uma língua serem dois sistemas distintos, a verdade é que é possível estabelecer uma relação entre os dois.

Os dados que foram encontrados e analisados no presente artigo apontam para a existência de erros que não se poderiam prever, apesar de, em alguns casos (nomeadamente o de ' $\mathrm{fl}$ '), os tipos de FN-Cs registadas parecerem emergir fundamentalmente em estruturas de aquisição tardia. Apesar da descoberta de FN-Cs na escrita encontrar motivações na ordem de aquisição da estrutura silábica nas crianças, esta não permite explicar a existência de tantas FN-Cs inesperadas, isto é, se a aquisição do sistema fonológico já existente impulsiona a aprendizagem da ortografia numa língua com escrita alfabética.

Em relação à primeira pergunta de investigação, nestes dados, as crianças recorrem a três estratégias essenciais de simplificação de sílabas com ataques ramificados: epêntese de vogal, elisão da segunda consoante do ataque ramificado e metátese. Quando as crianças recorrem ao processo de epêntese de vogal e à elisão da segunda consoante do ataque ramificado, estão a simplificar estruturas silábicas CCV em estruturas $\mathrm{CV}$, dado que o formato da sílaba CV é o universal e é o primeiro formato silábico a estabilizar na aquisição da estrutura silábica da criança (Freitas, 1997, 1998, 2001, 2003, 2016, 2017). Por sua vez, quando as crianças adotam o processo de metátese estão, por um lado, a simplificar sílabas CCV em sílabas CVC e, por outro, a 
preferir codas preenchidas ao invés de ataques ramificados ${ }^{19}$. Este fenómeno acontece porque a rima ramificada estabiliza, no processo de aquisição da estrutura silábica, antes dos ataques ramificados (cf. tabela 1). Nos dados encontrados neste estudo, o processo de metátese acontece em sequências com vibrante - a emergência desse segmento dá-se primeiro em coda (rima ramificada, CVC) e só depois em ataque ramificado.

\section{Considerações finais}

Adquirir um sistema escrito de uma língua não é uma tarefa fácil e intuitiva. É um percurso difícil, em que é necessário o domínio de regras que a mente de uma criança tem de processar.

Neste artigo, foi discutida a influência do conhecimento dos constituintes silábicos na aprendizagem do sistema ortográfico de uma língua como o PE. É sabido que as crianças, quando começam a aprender a escrita, produzem erros e que estes podem corresponder a vários tipos. Colocando o foco na sílaba, uma potencial unidade fonológica das línguas, foi posto em destaque o ataque ramificado. Este é um constituinte complexo e o último a ser adquirido no processo de aquisição do sistema fonológico do PE.

Reiterando a questão dos erros que as crianças dão na escrita nos primeiros anos de ensino básico (quando se iniciam na alfabetização), pretendíamos saber de que forma as crianças resolvem a grafia dos ataques ramificados na escrita, se o fazem com a mesma frequência nos dois anos de ensino que aqui foram estudados e se a ordem de aquisição da estrutura silábica conduz, de certa forma, à descoberta de FN-Cs na escrita dessas mesmas crianças. Neste último ponto, aludimos ao facto de poder ser o conhecimento fonológico que condiciona a aprendizagem da ortografia. Neste contexto, as respostas às perguntas de investigação subjacentes a este trabalho foram respondidas satisfatoriamente, mas deverão ser alvo de estudos mais aprofundados.

Deixamos o que não foi feito para investigação futura, nomeadamente, tentar perceber qual é a relação entre a frequência dos grupos consonânticos na língua e a quantidade de formas não convencionais, utilizando a ferramenta FrePOP (Frota et al., 2010) para analisar a frequência de ocorrência de cada grupo na língua; alargar este estudo aos alunos do $2^{\circ}$ e $4^{\circ}$ ano de outras zonas do país, pois o corpus EFFE-On tem sido recentemente alargado, incluindo dados de crianças de outras zonas dialetais. Isso permitiria confrontar os dados deste estudo com uma amostra mais alargada e de outras zonas do país. Seria, também, importante, estudar, por exemplo, a seleção das estratégias de resolução de ataques ramificados relativamente à posição da sílaba complexa na palavra (inicial e/ou medial), uma vez que «os tipos silábicos V e CCV predominam em início de palavra relativamente a outras posições, enquanto CVC e CVGN predominam em sílaba final» (Vigário et al., 2012).

\footnotetext{
${ }^{19}$ Em muitos casos, colocar a vogal ortográfica do núcleo antes do ' $r$ ' do ataque ramificado destruturado não possibilita que a consoante 'r' seja silabada sem ser em coda. Outro caso é o de < peresente> para < presente>. Neste, por um lado, há inserção desconstruindo o ataque ramificado e, por outro, o registo de uma vogal que pode ter correlação com a perceção da rótica, pois esta envolve sempre a produção, ainda que mínima, de um elemento de tipo vocálico à sua direita (Rodrigues, c.p).
} 


\section{Referências}

Afonso, C. \& Freitas, M. J. (2010) Consciência fonológica e desenvolvimento fonológico: o caso do constituinte Ataque em Português europeu. In Freitas, M. J., Gonçalves, A., Duarte, I. (eds.) Avaliação da Consciência Linguística: Aspectos fonológicos e sintácticos do Português. Lisboa: Ed. Colibri.

Alves, I., Costa, P., Lourenço-Gomes, M. \& Rodrigues, C. (2015) EFFE-On - Corpus Online de Escrita e Fala. Saber \& Educar, 20, pp. 24-33 (e-ISSN 1647-2144).

Alves, U. K. (2017) Teoria da Sílaba. In Matzenauer, C. \& d’Hora, D. Fonologia, fonologias: uma introdução. São Paulo: Editora Contexto.

Amorim, C. (2014) Padrão de aquisição de contrastes do PE: a interação entre traços, segmentos e sílabas. Dissertação de Doutoramento apresentada à Faculdade de Letras da Universidade do Porto.

Ávila, M. C. (2000) Aquisição do ataque silábico complexo: um estudo sobre crianças com idades entre 2:0 e 3:7. Dissertação de Mestrado em Linguística Aplicada apresentada à Universidade Católica de Pelotas.

Barbeiro, L. F. (2007) Aprendizagem da ortografia: princípios, dificuldades e problemas. Porto: Edições Asa.

Bisol, L. (org.) (1999) Introdução a estudos de fonologia do português brasileiro. Porto Alegre: EDIPUCRS. $2^{\circ}$ edição revista e aumentada.

Charrua, C. P. (2011) Aquisição Fonética-Fonológica do Português Europeu dos 18 aos 36 meses. Setúbal: Dissertação apresentada para cumprimento dos requisitos necessários à obtenção do grau de Mestre em Desenvolvimento e Perturbações da Linguagem na Criança, área de especialização em Terapia da Fala e Perturbações da Linguagem.

d'Andrade, E. \& Viana, M. do C. (1993) Sinérese, diérese e estrutura silábica. In Actas do IX Encontro Nacional da Associação Portuguesa de Linguística. Lisboa: APL. pp. 17-30.

Freitas, M. J. (1997) Aquisição da estrutura silábica do Português Europeu. Dissertação de Doutoramento apresentada à Faculdade de Letras da Universidade de Lisboa.

Freitas, M. J. (1998) Os segmentos que estão nas sílabas que as crianças produzem: localidade silábica e hierarquia de aquisição. In Mota, M. a. \& Marquilhas, R. (eds.) Actas do XIII Encontro Nacional da APL. Lisboa: APL, pp. 303-324.

Freitas, M. J. \& Faria, I. (1999) Order of acquisition for syllable structure: evidence from Portuguese children. In M. G. Pinto, J. Veloso \& B. Maia (eds.) Proceedings of the 5th International Congress of the International Society of Applied Psycholinguistics. Porto: Faculdade de Letras da Universidade do Porto. pp. 297-304.

Freitas, M. J. \& Santos, A. L. (2001) Contar histórias de sílabas. Lisboa: Edições Colibri.

Freitas, M. J. (2003) The acquisition of Onset clusters in European Portuguese. In Meisel, J. (org.) Probus. International Journal of Latin and Romance Linguistics, 15 (1), pp. 27-46.

Freitas, M. J., Alves, D. e Costa, T. (2007) O conhecimento da língua: desenvolver a consciência fonológica. Lisboa: Ministério da Educação Direcção-Geral de Inovação e de Desenvolvimento Curricular.

Freitas, M. J. (2016) A sílaba na gramática do adulto e na aquisição da língua materna. In Martins, A. M. e Carrilho, E. (Eds.) Manual de Linguística Portuguesa. Berlin: De Gruyter.

Freitas, M. J. (2017) Aquisição da fonologia em língua materna: a sílaba. In Freitas, M. J. e Santos, A. L. Aquisição de língua materna e não materna. Questões gerais e dados do português. Language Science Press: Textbooks in Language Sciences. pp. 71-94.

Frota, S., M. Vigário, F. Martins \& M. Cruz (2010) FrePOP. Version 1.0. (ISBN 978-989-95713-2-7). Online database available http://frepop.fl.ul.pt.

Gálea, D. E. S. (2008) Percurso da aquisição dos encontros consonantais, fonemas e estruturas silábicas em crianças de 2:1 a 3:0 anos de idade. Dissertação de Doutoramento apresentada à Faculdade de Filosofia, Letras e Ciências Humanas da Universidade de São Paulo.

Gleason, H. A. (1961) Introdução à Linguística Descritiva. Lisboa: Fundação Calouste Gulbenkian. 
Gussenhoven, C. \& Jacobs, H. (1998) Understanding Phonology. London: Arnold.

Guimarães, M. R. (2005) Um estudo sobre a Aquisição da ortografia nas séries iniciais. Dissertação de Mestrado apresentada ao Programa de Pós-Graduação em Educação, da Universidade Federal de Pelotas, como requisito para obtenção do título de Mestre.

Leitão, A. F. S. (2016) Refletir sobre ortografia no $1^{o}$ ciclo do Ensino Básico - um estudo com alunos do $2^{o}$ ano. Relatório da Componente de Investigação de Estágio III do Mestrado em Educação Pré-Escolar e Ensino do $1^{\circ}$ Ciclo do Ensino Básico - Instituto Politécnico de Setúbal (IPS).

Lopes, F. T. F. (2011) Dificuldades de escrita: o erro ortográfico, revelador do conhecimento metafonológico do escrevente aluno do ensino básico. Dissertação de Mestrado apresentada à Faculdade de Letras da Universidade de Coimbra.

Mateus, M. H. M. \& d'Andrade, E. (2000) The phonology of Portuguese. Oxford: Oxford University Press.

Mateus, M. H. M. et al. (2003) Gramática da Língua Portuguesa. Lisboa: Editorial Caminho.

Miranda, A. R. M. (2007). Aspetos da escrita espontânea e da sua relação com o conhecimento fonológico. In Lamprecht, R. R. Aquisição da Linguagem: estudos recentes no Brasil. Porto Alegre: EDIPUCRS.

Miranda, A. R. M. \& Matzenauer, C. (2010) Aquisição da fala e da escrita: relações com a fonologia. In Cadernos de Educação, 35. Pelotas: UFPel, pp. 359-405.

Miranda, I. C. C. \& Silva, T. C. (2011) Aquisição de encontros consonantais tautossilábicos: uma abordagem multirrepresentacional. In Revista Lingüística, 7 (1). Rio de Janeiro: UFRJ, pp. 14-30.

Nespor, M. \& Vogel, I. (2007) Prosodic phonology: with a new foreword. Berlin: Mouton de Gruyter.

Pinto, M. G. L. C. (1997) A ortografia e a escrita em crianças portuguesas nos primeiros anos de escolaridade. In Revista da Faculdade de Letras do Porto - Línguas e Literaturas, 14, pp. 7-58

Ramalho, A. M. M. C. (2017) Aquisição fonológica na criança: tradução e adaptação de um instrumento de avaliação interlinguístico para o português europeu. Tese apresentada à Universidade de Évora para a obtenção do Grau de Doutor em Linguística.

Ribas, L. (2003) Onset complexo: características da aquisição. In Letras de Hoje, 38 (2), pp. 23-31. Brasil: Porto Alegre.

Ribas, L. (2004) Sobre a aquisição do onset complexo. In Lamprecht, R. R. (org.) Aquisição fonológica do Português: Perfil de desenvolvimento e subsídios para terapia. Porto Alegre: Artmed, pp. 151-164

Rodrigues, C., Lourenço-Gomes, M. C., Alves, I., Janssen, M., Gomes, I. L. (2015) EFFE-On - Escreves como falas - Falas como escreves? (Online corpus of writing and speech of children in the early years of schooling). Lisboa: CLUL.

Santos, R. (2013) Aquisição de grupos consonânticos e seu impacto nos desempenhos escritos no $1^{\circ}$ Ciclo do Ensino Básico. Tese de Mestrado apresentada à Faculdade de Letras da Universidade de Lisboa.

Santos, Rita, M. João Freitas \& João Veloso (2014) Grupos consonânticos na escola: desenvolvimento fonológico e conhecimento ortográfico. In Revista Diacrítica-Ciências da Linguagem. Universidade do Minho, vol. 28 (1), nº 1, pp. 407-436.

Selkirk, E. (1982) The Syllable. In Hulst, H. \& Smith, N. (eds.) The Structure of Phonological Representations (Part II). Dordrecht Foris, pp. 337-383.

Selkirk, E. (1984) On the major class features and syllable theory. In Aronoff, M., Oehrle, R. (org) Language Sound Structure. Cambridge, Mass: MIT Press, pp. 107-136.

Sousa, C. (1999) A língua escrita: um processo de apropriação: O erro ortográfico como hipótese construtiva. Projeto final de CESE em Educação Infantil e Básica Inicial, no ramo de Língua Portuguesa e Literatura Infantil apresentado ao Instituto de Estudos da Criança da Universidade do Minho.

Veloso, J. (2003) Da influência do sistema ortográfico sobre o conhecimento fonológico. Estudo longitudinal de um grupo de crianças falantes nativas do Português Europeu. Dissertação de Doutoramento apresentada à Faculdade de Letras da Universidade do Porto. 
Vigário, M. \& Falé, I. (1993) A sílaba do Português Fundamental: uma descrição e algumas considerações de ordem teórica. In Actas do IX Encontro Nacional da Associação Portuguesa de Linguística. Lisboa: APL, pp. 465-478.

Vigário, M., F. Martins \& S. Frota (2006) A ferramenta FreP e a frequência de tipos silábicos e classes de segmentos no Português. In Fátima Oliveira \& Joaquim Barbosa (eds.) XXI Encontro da Associação Portuguesa de Linguística. Textos Seleccionados. Lisboa: APL, pp. 675-687.

Vigário, M. et al. (2012) Frequência na Fonologia do Português: recursos e aplicações. In Costa, A. \& Duarte, I. (eds.) Nada na linguagem lhe é estranho. Estudos em homenagem a Isabel Hub Faria. Porto: Edições Afrontamento, pp. 613-631. 